\title{
FRACTURE MANAGEMENT IN PATIENTS WITH HAEMOPHILIA
}

\author{
Edward Feil, George Bentley and Charles R. Rizza, Oxford, England \\ From the Nuffield Department of Orthopaedic Surgery, Nuffield Orthopaedic Centre, and the \\ Oxford Haemophilia Centre
}

Fractures in patients with haemophilia are rare (Flatmark 1964; Ahlberg and Nilsson 1967, Kemp and Matthews 1968). This is because haemophilia is uncommon (three to four per 100,000 in Great Britain) and because of the relatively protected life which many haemophilic patients lead. From 1968 to 1970 five haemophilic patients with fractures were treated at the Nuffield Orthopaedic Centre and Oxford Haemophilia Centre; the principles of management evolved during their treatment are described here. Two of the patients had antibodies to factor VIII which produced special problems (Table I).

TABLE I

Clinical Material

\begin{tabular}{|c|c|c|c|c|c|c|c|}
\hline \multirow{2}{*}{$\begin{array}{c}\text { Case } \\
\text { number }\end{array}$} & \multirow{2}{*}{$\begin{array}{c}\text { Age } \\
\text { (years) }\end{array}$} & \multirow{2}{*}{$\begin{array}{c}\text { Coagulation } \\
\text { defect }\end{array}$} & \multirow{2}{*}{$\begin{array}{l}\text { Antibodies } \\
\text { to AHG }\end{array}$} & \multirow{2}{*}{ Type of fracture } & \multicolumn{2}{|c|}{ Treatment } & \multirow{2}{*}{$\begin{array}{c}\text { Time to } \\
\text { (monion } \\
\text { months) }\end{array}$} \\
\hline & & & & & Local & Systemic & \\
\hline 1 & 9 & $\begin{array}{l}\text { Factor VIII } \\
0 \text { per cent }\end{array}$ & - & $\begin{array}{l}\text { Spiral fracture } \\
\text { shaft of femur }\end{array}$ & Plaster spica & Cryoprecipitate & 3 \\
\hline 2 & 42 & $\begin{array}{l}\text { Factor VIII } \\
0 \text { per cent }\end{array}$ & - & $\begin{array}{l}\text { Oblique fracture } \\
\text { femoral shaft }\end{array}$ & $\begin{array}{l}\text { Thomas splint. } \\
\text { Compression plate } \\
\text { and plaster spica } \\
\text { at } 21 \text { days }\end{array}$ & Human AHG & 8 \\
\hline 3 & 49 & $\begin{array}{l}\text { Factor VIII } \\
20 \text { per cent }\end{array}$ & - & $\begin{array}{c}\text { Transverse fracture } \\
\text { olecranon }\end{array}$ & $\begin{array}{l}\text { Open reduction. } \\
\text { Lag screw fixation }\end{array}$ & Human AHG & 2 \\
\hline 4 & 21 & $\begin{array}{l}\text { Factor VIII } \\
0 \text { per cent }\end{array}$ & $\begin{array}{l}\text { To human } \\
\text { AHG }\end{array}$ & $\begin{array}{l}\text { Oblique fracture } \\
\text { lower shaft } \\
\text { tibia and fibula }\end{array}$ & $\begin{array}{l}\text { Reduction and } \\
\text { full leg } \\
\text { plaster cast }\end{array}$ & $\begin{array}{l}\text { Porcine AHG } \\
\text { Cryoprecipitate }\end{array}$ & 8 \\
\hline 5 & 64 & $\begin{array}{l}\text { Factor VIII } \\
0 \text { per cent }\end{array}$ & $\begin{array}{c}\text { To human } \\
\text { and porcine } \\
\text { AHG }\end{array}$ & $\begin{array}{l}\text { Compound } \\
\text { transverse fracture } \\
\text { upper tibia }\end{array}$ & $\begin{array}{l}\text { Wound toilet } \\
\text { and suture. } \\
\text { Direct pressure } \\
\text { for haemostasis. } \\
\text { Plaster backslab }\end{array}$ & $\begin{array}{l}\text { Porcine AHG } \\
\text { Cryoprecipitate }\end{array}$ & 5 \\
\hline
\end{tabular}

\section{CASE REPORTS}

Case 1-In December 1968 a boy aged nine with 0 per cent factor VIII slipped and fell, sustaining a spiral fracture of the left femur and a haemarthrosis of the left knee (Fig. 1). There was a past history of recurrent haemarthroses of the left knee, with a restricted range of movement of 10 to 80 degrees. On admission, he was given a transfusion of cryoprecipitate. The left knee was aspirated and a plaster-of-Paris hip spica was applied; radiographs in the plaster showed satisfactory alignment. After three months further radiographs showed union of the fracture and the plaster was removed, the limb was mobilised and a protective caliper with a knee lock was fitted. The knee regained a range of 15 to 70 degrees.

Comment-Before the injury the boy had restricted movement in the knee from repeated haemarthroses. This type of fracture is known to be stable in children, so that the treatment by external splinting in a plaster spica was satisfactory. Union occurred within three months. Such a fracture of the shaft of the femur is unstable in adults and produces problems in management if stability is not achieved early as is illustrated by the next case. 


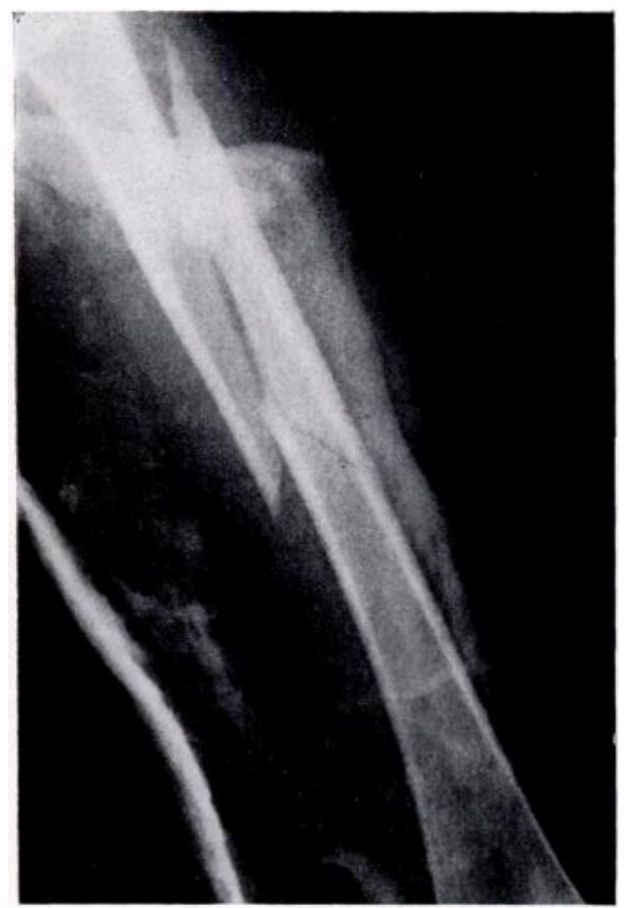

Fig. 1

Figure 1. Case 1-Antero-posterior radiograph of left femur showing a spiral fracture of the shaft supported in a plaster-of-Paris shell.

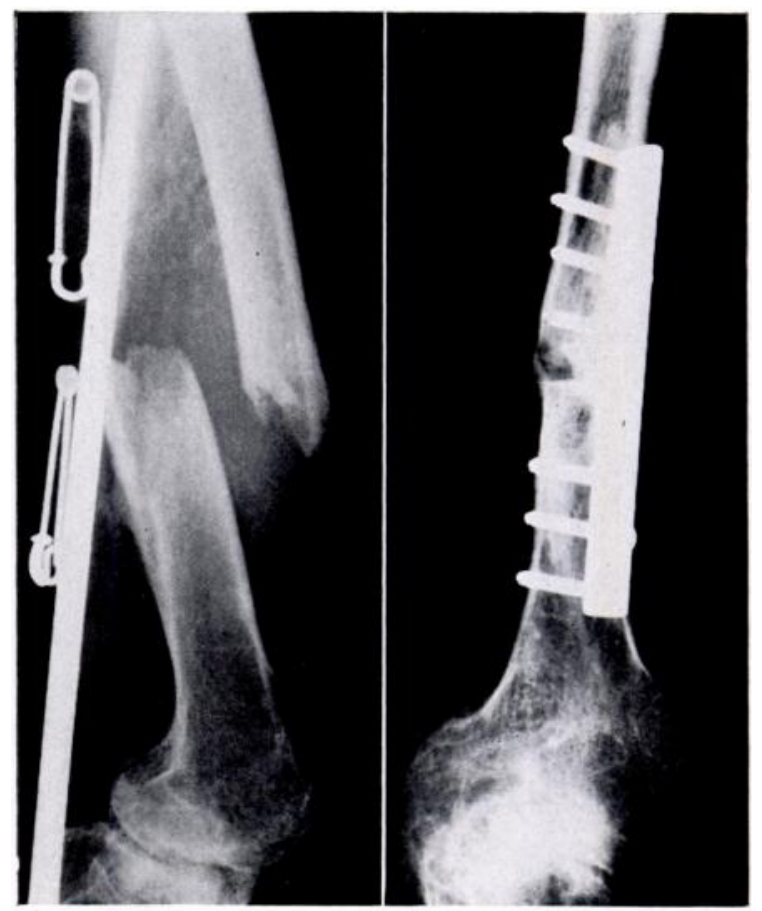

FIG. 2

Fig. 3

Figure 2. Case 2-Radiograph of the shaft of the femur before operation. The wide separation of the fragments of the oblique fracture is seen on the lateral film. Figure 3Radiograph eight months after injury when union was present.

Case 2-A man aged forty-two with 0 per cent factor VIII had a long history of recurrent haemarthroses in the left knee which had caused a severe arthropathy with lateral dislocation of the patella. In January 1970 he slipped at home and sustained a closed oblique fracture of the midshaft of the right femur. He received transfusions of cryoprecipitate for three days after the fracture. Eleven days later he had a recurrence of pain and swelling at the fracture site which was treated with a three-day course of cryoprecipitate with relief of pain. He did well until twenty days later when he again developed pain and swelling at the fracture site. Radiographs showed wide separation of the fragments with posterior displacement of the distal fragment (Fig. 2).

He was transferred to the Nuffield Orthopaedic Centre on the following day. After administration of antihaemophilic globulin (AHG), the fracture was explored. A large cystic swelling containing two litres of partially clotted blood was found surrounding the bone ends. The fragments were fixed with an eight-hole compression plate and a full leg hip spica was applied. The post-operative course was complicated by haemorrhages into the elbows: these were treated by immobilisation for a few days, with factor VIII replacement therapy. The spica was retained for six months. Walking with crutches then began, in a caliper. Radiographs showed the fracture to be united eight months after the injury, when the limb was left free (Fig. 3). The final range of movement at the left knee was 0 to 20 degrees, the same as it had been before the fracture.

Comment-The fracture sustained by this patient was of an unstable type which is often complicated by interposition of muscle between the bone ends. Conservative treatment usually needs skeletal traction by a pin through the upper tibia; this is potentially hazardous in a haemophilic patient because of the possibility of bleeding from the pin track and infection. Moreover, slight movement at the fracture site is inevitable when traction alone is used, and 
in haemophilia this may lead to repeated haemorrhages with the risk of cyst formation in the soft tissues, as in this patient, or of pseudotumour of bone, as reported by Ahlberg and Nilsson (1967). For these reasons it was thought best to use internal fixation to stabilise the fracture and the soft tissues.

Case 3-A man aged forty-nine with mild haemophilia, with 20 per cent of factor VIII, fell at work in December 1969 and sustained a closed transverse fracture of the right olecranon (Fig. 4). Six days after the fracture open reduction and fixation by a lag screw was performed (Fig. 5). He was given human AHG before operation and for three days afterwards. The limb was splinted in a plaster back slab and held in a triangular sling for three weeks, and then mobilised. The fracture healed without any complications and the final range of movement in the elbow

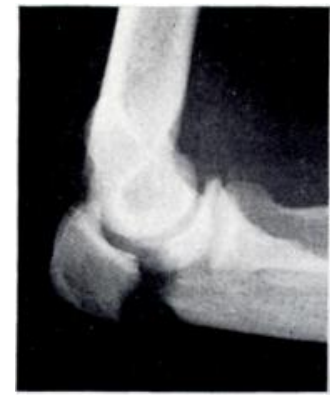

FIG. 4

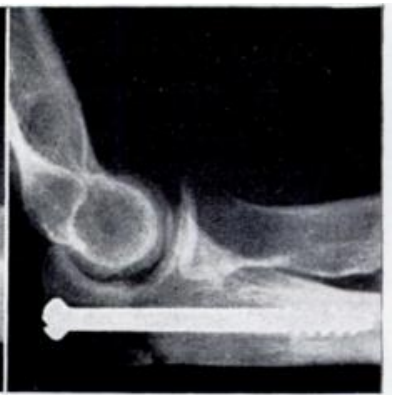

FIG. 5

Case 3-Lateral radiographs of the right elbow before (Fig. 4) and after (Fig. 5) internal fixation of the fracture of the olecranon. was from 5 to 120 degrees.

Comment-Internal fixation is the only satisfactory method of treating this fracture, but immobilisation in a plaster is needed in haemophilic patients for two to three weeks after operation to achieve primary wound healing and prevent bleeding from the wound edges.

Case 4-A man aged twenty-one had haemophilia with 0 per cent factor VIII. He developed antibodies to factor VIII during the course of treatment. He was transferred to us sixteen days after he had fractured his left tibia and fibula in a road accident. He also had a slight head injury and several skin lacerations. He was treated initially with doses of porcine AHG and cryoprecipitate; the fracture was reduced and immobilised in plaster. He was then found

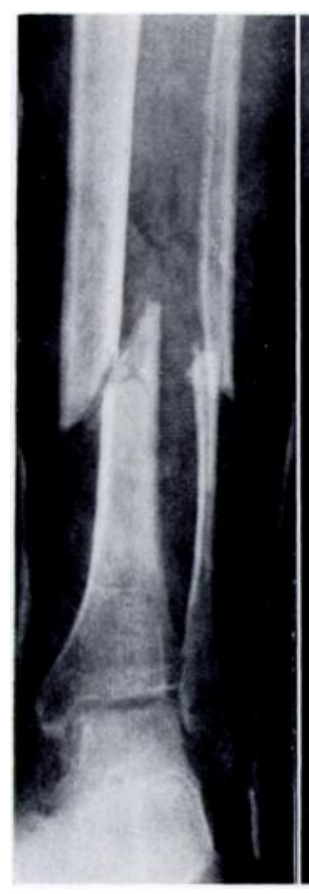

Fig. 6

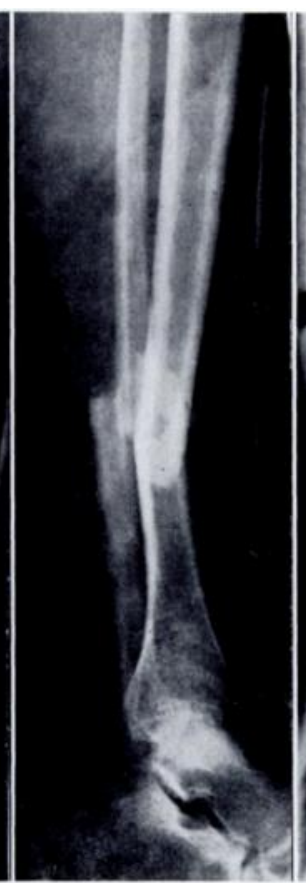

Fig. 7

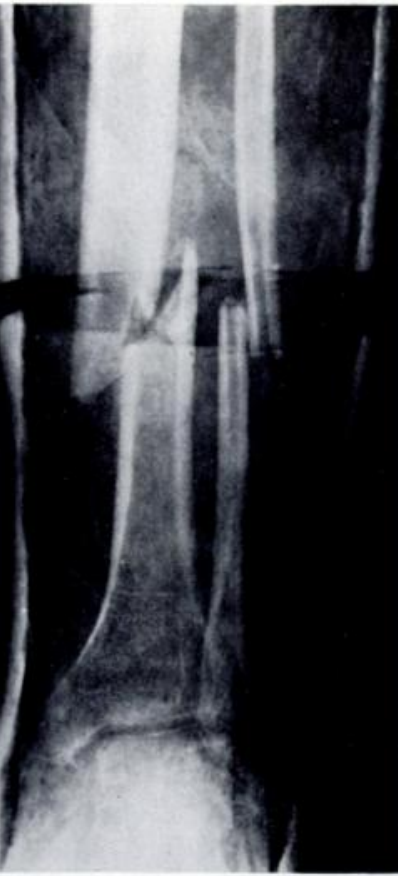

Fig. 8

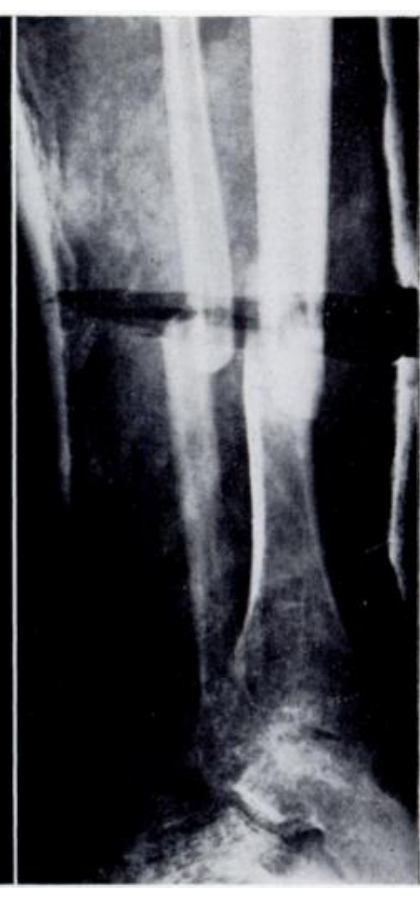

Fig. 9

Case 4-Figures 6 and 7 are antero-posterior and lateral radiographs of an oblique fracture of the tibia with backward angulation. Figures 8 and 9 are the radiographs after wedging of the cast. There is good alignment.

VOL. 56 B, NO. 4, NOVEMBER 1974 
to have antibodies to factor VIII. Radiographs showed a fracture of the lower shaft of the left tibia and fibula with shortening and backward angulation (Figs. 6 and 7). At three weeks from the time of injury the cast was wedged, without AHG cover because of the factor VIII antibodies, and a satisfactory position obtained (Figs. 8 and 9). No bleeding occurred. $\mathrm{He}$ was discharged from hospital non-weight-bearing with crutches; weight-bearing in the cast began at eight weeks. The plaster was removed eight months after the injury and radiographs showed the fracture to be healed in good position.

Comment-The presence of antibodies to factor VIII precluded internal fixation of the fractures of the tibia and fibula in this patient. The laboratory facilities to detect the extent of deficiency of factor VIII, the presence of antibodies to factor VIII, and the response to any treatment should be available when such patients require treatment for severe injuries. The management of the next patient indicates the importance of careful control of haemostasis in haemophilia.

Case 5-A man aged sixty-four was admitted to the Nuffield Orthopaedic Centre in October 1970. In 1966 he had presented to the local hospital with a two-year history of intermittently painful swollen joints and a scattered purpuric rash. He was found to have a circulating

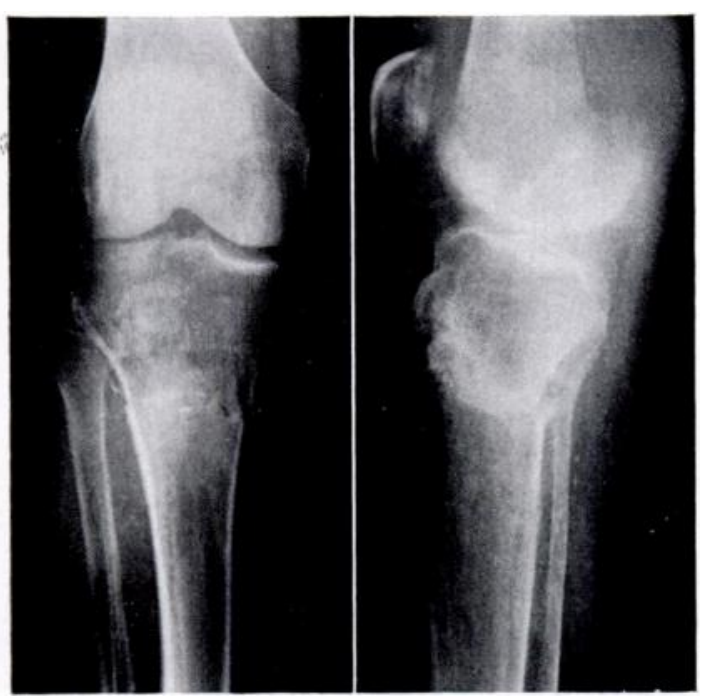

Fig. 10

Case 5-Antero-posterior and lateral radiographs of right knee showing a transverse fracture of the upper tibial shaft with slight forward angulation. antibody directed against factor VIII. Investigations suggested a diagnosis of polyarteritis nodosa and his symptoms were considered to be manifestations of a hypersensitivity reaction. He was treated with prednisolone 5 milligrams three times each day. During the next four years he was able to continue working as a clerk in an engineering company but continued to have recurrent purpura and joint swellings despite continuous prednisolone therapy and a three-month course of azathioprine.

The day before his admission he had tripped over a steel bar and sustained a compound transverse fracture of the right tibia 5 centimetres below the knee joint (Figs. 10 and 11). Primary treatment had been carried out at a local hospital, a plaster splint being applied after reduction of the fracture and wound repair. Extensive bleeding from the fracture site had continued throughout the operation despite the transfusion of nine pints of blood and thirty-five donor units of cryoprecipitate. He was given ten ampoules of porcine AHG and transferred to the Nuffield Orthopaedic Centre.

On admission, incubation of the patient's plasma with human and porcine factor VIII demonstrated the presence of an antibody directed against both types of factor VIII. Radiographs showed good position of the fracture. Factor VIII replacement therapy was continued with porcine AHG, given in a dosage of 15 ampoules $(8,500$ units of factor VIII) twice daily and the leg was immobilised in a plaster backslab on a Thomas splint. A persistent ooze of blood continued from the wound despite achieving adequate haemostatic levels of circulating factor VIII ranging from 22 to 43 per cent of normal. A low platelet count, probably the result of multiple blood transfusion and porcine AHG therapy, was thought to be the main cause of the continued oozing. Further examination of the wound twenty-four hours later showed oozing from the skin edges. Because bleeding from thrombocytopaenia, in contradistinction to bleeding from clotting factor deficiencies, can often be controlled by pressure, 
local pressure was applied to the wound edges using a padded clamp. The porcine AHG was temporarily withheld and three doses of cryoprecipitate of forty donor units $(2,500$ units of factor VIII) each were given at twelve-hourly intervals in an attempt to allow the platelet count to rise. However, the levels of circulating factor VIII achieved by these doses were less than those obtained using porcine AHG, which was therefore started again. With this programme of local pressure and systemic therapy the bleeding stopped within forty-eight hours and AHG therapy with porcine AHG was continued for ten days from admission (Fig. 12). The patient's recovery from the fracture was uneventful, although he had repeated subcutaneous

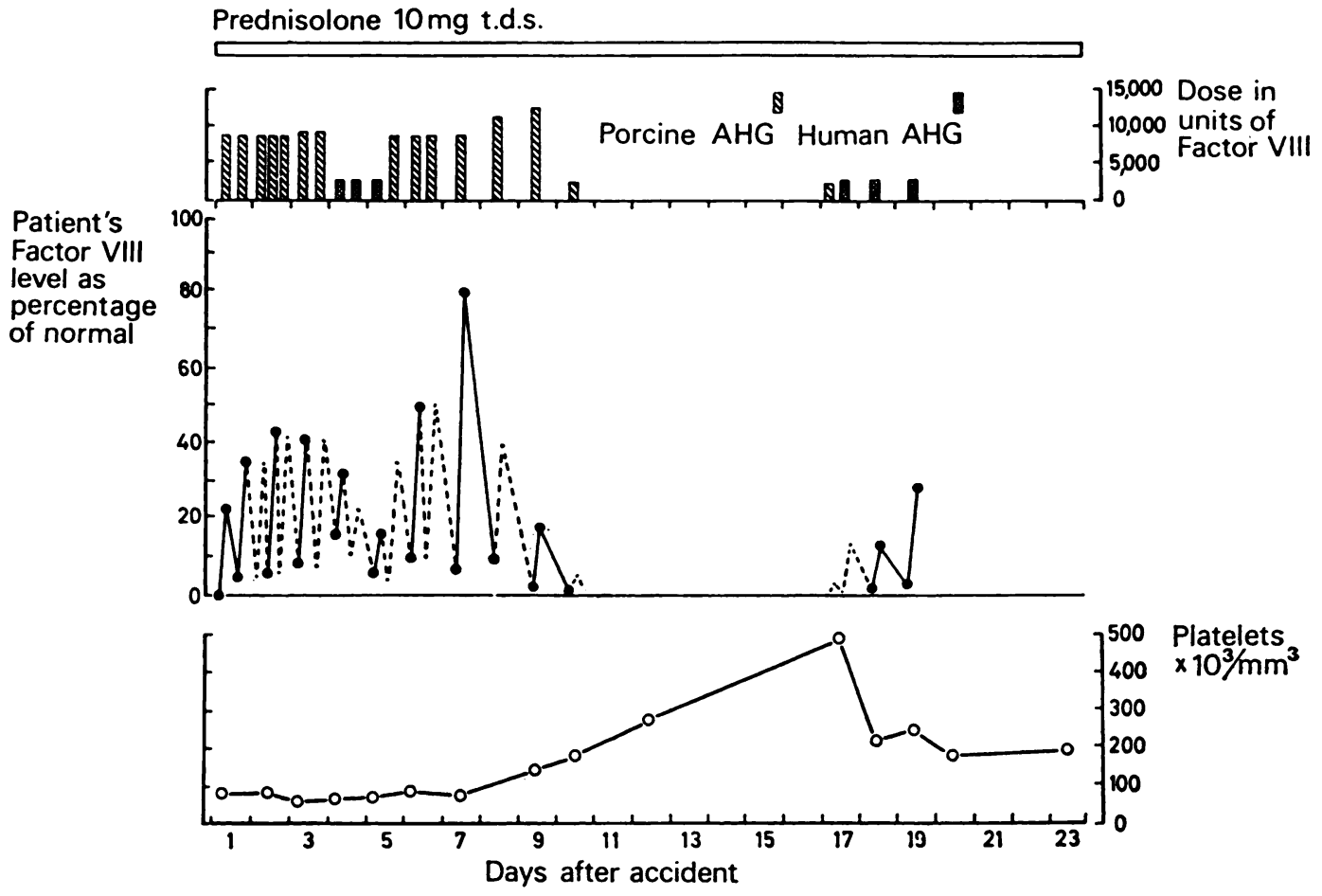

Fig. 12

Scheme showing the regime of systemic factor VIII therapy in Case 5.

haemorrhages on the trunk and buttocks. After bed rest for six weeks he began to bear weight in a full leg plaster-of-Paris cast. Two months after the accident he was discharged from hospital. The fracture was healed clinically and radiographically five months after the accident.

\section{DISCUSSION}

There are few reports of fractures in haemophiliacs. Cases 4 and 5 are to our knowledge the first reported in haemophiliacs with antibodies to factor VIII. Case 5 illustrates several problems which arise in treatment of patients with antibodies.

As is often the case the antibodies were more active against human factor VIII than against pig factor VIII (Biggs 1966). The patient bled persistently from the skin edges probably as a result of thrombocytopenia which is a well known complication of treatment with large doses of porcine AHG. Application of firm pressure to the wound together with systemic therapy controlled the bleeding. 
The presence of antibodies to factor VIII in the patient's blood makes antihaemophilic replacement therapy extremely difficult because the transfused factor VIII is rapidly destroyed. In addition to this, the giving of factor VIII produces a sharp rise in the patient's antibody titre within six to ten days of the start of transfusion therapy. It is important therefore, once transfusion therapy has been started, to be vigorous in treatment so as both to obtain and maintain haemostasis during the first six to seven days because thereafter the patient may not be treatable with antihaemophilic replacement once the antibody level has risen. However, in life-threatening situations, as in Case 5, blood loss is best treated with infusions of washed packed red cells. Because the antibodies are less active to porcine than to human AHG, the giving of high doses of porcine AHG (8,000 to 16,000 units), as in Case 5, can produce dramatic clinical benefit despite failure to attain levels of factor VIII that can be demonstrated in the laboratory. The explanation of the beneficial effect is either that inactivation of factor VIII is not instantaneous or that a relative excess of factor VIII is produced by saturating all the antibodies.

General management of fractures in haemophilia-The three principles involved in management of fractures in a haemophilic patient are, first, the production of initial haemostasis, second, to maintain haemostasis during healing, and third, the rigid immobilisation of the fracture (Kemp and Matthews 1968). This involves appropriate systemic treatment and the correct local treatment of both the fracture and the injured soft tissues. This is the special responsibility of the orthopaedic surgeon.

Systemic treatment must begin by replacing the deficient factor. A large enough dose of AHG should be given to maintain haemostasis until the next transfusion. The more extensive the injury, the higher the concentration that will be needed. Ahlberg and Nilsson (1967) suggested a level of at least 20 per cent of factor VIII. Treatment should be continued over the time needed to stabilise the fracture and this depends on the efficacy of the local treatment.

It is essential to assess the stability of the fracture at the time of initial treatment. Failure to do so may involve the patient in further bleeding, pain and late manipulation or operation which create hazards of renewed haemorrhage as in Case 2. We consider that conservative treatment is satisfactory in children and in stable fractures but disagree with Ahlberg and Nilsson (1967) who advised conservative treatment if possible in all haemophiliacs.

The early internal fixation of unstable fractures is necessary to stabilise the fracture and the surrounding soft tissues, and to allow mobilisation of neighbouring joints when possible. Examination of the affected limb is also facilitated. In addition the stability achieved prevents formation of soft tissue and bony cysts caused by repeated haemorrhage at the fracture site.

Internal fixation may reduce the possibility of delayed union and malunion associated with poorly-positioned fractures (Flatmark 1964). A complete plaster-of-Paris cast should not be used unless haemostasis is assured and the swelling is diminishing because of the potential risk of nerve or blood vessel compression. Cases 2 and 3 both show that internal fixation with adequate AHG therapy is a safe and dependable way of treating unstable fractures in haemophilia. Generally the presence of circulating antibodies to AHG precludes internal fixation of fractures.

Etiology of fractures in haemophilia-In Cases 2, 3 and 5 the fractures occurred from trivial injuries, as did several reported by previous authors (Jordan 1958, Ikkala 1960, Flatmark 1964, Kemp and Matthews 1968). All three fell from the standing position. The combination of poor muscle function, especially of the quadriceps, limitation of joint movement and osteoporosis secondary to repeated haemarthroses predisposes to such fractures.

Healing of fractures in haemophilia-It is interesting that in Cases 2, 3, 4 and 5, fracture healing occurred with little callus, suggesting that healing was largely endosteal. This may be simply explained by the requirement for immobility in haemophilic patients and internal stabilisation so that little periosteal new bone was formed. 


\section{SUMMARY}

1. The management of fractures in five patients with haemophilia is described: two patients had antibodies to antihaemophilic globulin.

2. The principles of management of injured haemophilia patients are described, as are the special problems in patients with antibodies to AHG.

3. Stability of the fragments must be achieved to prevent the hazards of displacement of the fracture, recurrent bleeding and pseudotumour formation which may threaten viability of the limb.

4. Stabilisation of potentially unstable fractures can be achieved at the onset by internal fixation. Plaster casts should be reserved for stable fractures or fractures occurring in young children.

We wish to thank Professor R. B. Duthie for his advice and for permission to review these patients; and Mr R. Emmanuel, the Photographic Department, Nuffield Orthopaedic Centre, for the illustrations.

\section{REFERENCES}

Ahlberg, A., and Nilsson, I. M. (1967): Fractures in haemophiliacs with special reference to complications and treatment. Acta chirurgica Scandinavica, 133, 293-302.

BigGS, R. (1966): The laboratory and clinical diagnosis of patients with coagulation defects. In Treatment of Haemophilia and other Coagulation Disorders, p. 39. Edited by R. Biggs and R. G. MacFarlane. Oxford: Blackwell Scientific Publications.

Flatmark, A. L. (1964): Fracture union in the presence of delayed blood coagulation. Acta chirurgica Scandinavica, Supplementum 344.

IKKALA, E. (1960): Haemophilia. Scandinavian Journal of Clinical and Laboratory Investigation, Vol. 12, Supplement 46.

Jordan, H. H. (1958): Hemophilic Arthropathies. Springfield, Illinois: Charles C. Thomas.

KEMP, H. S., and MATTHEWS, J. M. (1968): The management of fractures in haemophilia and Christmas disease. Journal of Bone and Joint Surgery, 50-B, 351-358.

VOL. 56 B, NO. 4, NOVEMBER 1974 